\title{
Пленение излучения и субподзонный пик в спектрах квантового выхода фотоэмиссии $p-\operatorname{GaAs}(\mathrm{Cs}, \mathrm{O})$
}

\author{
Д.Е. Протопопов ${ }^{1,2}$, В.С. Хорошилов ${ }^{1,2}$, Д.М. Казанцев ${ }^{1,2}$, Г.Э. Шайблер ${ }^{1,2}$, В.Л. Альперович ${ }^{1,2}$ \\ ${ }^{1}$ Институт физики полупроводников им. А.В.Ржанова СО РАН, 630090, Новосибирск \\ ${ }^{2}$ Новосибирский государственный университет, 630090, Новосибирск \\ тел:+7 (383)330-98-74, эл.nочта: alper@isp.nsc.ru
}

DOI 10.34077/RCSP2021-130

Поверхности $p$-GaAs c адсорбированными слоями цезия и кислорода широко используются для создания фотокатодов с эффективным отрицательным электронным сродством $(\mathrm{O})$ [1]. Поверхности полупроводников с относительно небольшим (0.2-0.4 эВ) положительным электронным сродством (ПЭС) привлекают внимание в связи с возможностью использования фотонно-усиленной термоэлектронной эмиссии (photon-enhanced thermionic emission, PETE) для повышения эффективности преобразователей солнечной энергии [2]. В [3,4] методом спектроскопии квантового выхода фотоэмиссии изучен переход между состояниями с отрицательным и положительным сродством путем нанесения избыточного цезия или кислорода на оптимально активированную поверхность $\mathrm{p}-\mathrm{GaAs}(\mathrm{Cs}, \mathrm{O})$. Зависимости вероятностей выхода горячих и термализованных электронов от величины сродства, полученные сопоставлением измеренных спектров с расчетом, свидетельствуют о смене механизма эмиссии при переходе от ОЭС к ПЭС [3]. При этом, в области энергий фотонов ћ $\omega$ ниже ширины запрещенной зоны $\varepsilon_{\mathrm{g}}$, проявились ранее не наблюдавшиеся спектральные особенности в виде отчетливого "плеча", а при некоторых условиях - пика, которые не получили ясного объяснения [4]. Данная работа посвящена выяснению возможных причин этих особенностей.

Эксперименты проводились в сверхвысоковакуумной установке на эпитаксиальных слоях сильнолегированного $p$-GaAs толщиной 4 мкм с концентрацией дырок $7 \times 10^{18} \mathrm{~cm}^{-3}$, выращенных на полуизолирующих подложках GaAs. Чистая поверхность $p$-GaAs приготавливалась химическим удалением оксидов и последующим отжигом в вакууме. Ток фотоэмиссии измерялся в геометрии "на отражение". Установлено, что при нанесении цезия на поверхность $\mathrm{GaAs}(\mathrm{Cs}, \mathrm{O})$, предварительно активированную до состояния с ОЭС, происходит переход от ОЭС к ПЭС, и в спектре фотоэмиссии проявляется отчетливый пик при энергии фотонов $ћ \omega \approx 1.365$ эВ, меньшей ширины запрещенной зоны GaAs $\varepsilon_{\mathrm{g}} \approx 1.42$ эВ. При нанесении избыточного кислорода данная спектральная особенность проявлялась существенно слабее, в виде плеча. Возможное причина этих особенностей связана с "пленением" излучения в образце и эффектом Франца-Келдыша в поверхностном электрическом поле. Действительно, свет с энергией квантов в области прозрачности подложки эффективно захватывается в структуре благодаря диффузному отражению от неполированной (матовой) задней поверхности подложки и эффекту полного внутреннего отражения. Однако для энергий фотонов, достаточно близких к ширине запрещенной зоны, этот свет может поглощаться вблизи поверхности благодаря эффекту Франца-Келдыша в поверхностном электрическом поле, который приводит к сдвигу края поглощения в сторону меньших энергий фотонов. Несмотря на малость толщины области поверхностного поля $w \sim 10$ нм, значимое поглощение света и последующая эмиссия электронов возможны, по-видимому, благодаря многократному прохождению плененного излучения через эту область. При увеличении энергии фотонов, эффект отражения от задней грани пропадает за счет сильного поглощения в подложке, и фотоэмиссия, вызванная плененным излучением, уменьшается. Установлено, что полировка задней грани подложки приводит к исчезновению пика в спектре. Таким образом, эффект пленения излучения доказан экспериментально. В то же время, механизм поглощения плененного излучения остается пока не вполне ясным. В работе обсуждаются, помимо эффекта Франца-Келдыша в поверхностном поле, возможное поглощение в адсорбированных атомах цезия между уровнями 6s и 6р, модифицированными (сдвинутыми по энергии и уширенными) благодаря адсорбции на поверхности, а также поглощение в самом эпитаксиальном слое $p$-GaAs.

Работа выполнена при финансовой поддержке РФФИ, грант № 20-02-00355.

\section{Лumepamypa}

[1] V.V. Bakin et al., e-J. Surf. Sci. Nanotech. 5, p.80-88 (2007).

[2] J.W. Schwede et al., Nat. Mater. 9, 762 (2010).

[3] A.G. Zhuravlev, V.S. Khoroshilov, V.L. Alperovich, Appl. Surf. Sci. 2019483, 895 (2019).

[4] D.E. Protopopov et al., J. Phys.: Conf. Ser. 2020, v. 1695, 012105 